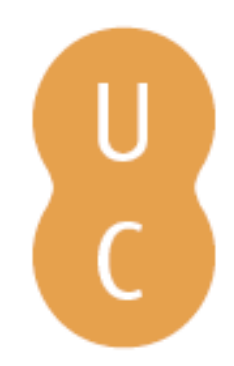

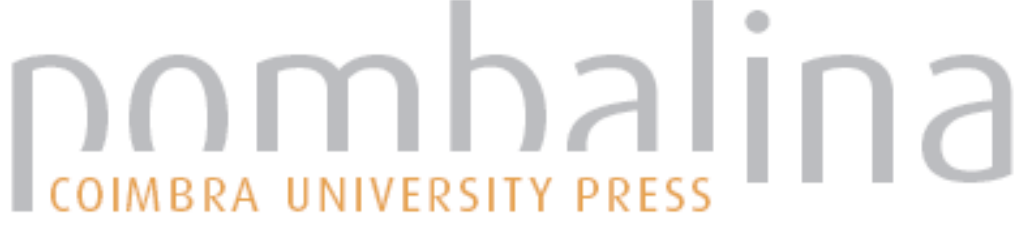

\section{Health education factsheet on mental health in the elderly}

Autor(es): $\quad$ Reis, Ana Teresa de Sousa; Martins, Anabela Correia

Publicado por: Imprensa da Universidade de Coimbra

URL

persistente:

URI:http://hdl.handle.net/10316.2/32542

DOI:

DOI:http://dx.doi.org/10.14195/978-989-26-0732-0_19

Accessed : $\quad$ 26-Apr-2023 15:50:57

A navegação consulta e descarregamento dos títulos inseridos nas Bibliotecas Digitais UC Digitalis, UC Pombalina e UC Impactum, pressupõem a aceitação plena e sem reservas dos Termos e Condições de Uso destas Bibliotecas Digitais, disponíveis em https://digitalis.uc.pt/pt-pt/termos.

Conforme exposto nos referidos Termos e Condições de Uso, o descarregamento de títulos de acesso restrito requer uma licença válida de autorização devendo o utilizador aceder ao(s) documento(s) a partir de um endereço de IP da instituição detentora da supramencionada licença.

Ao utilizador é apenas permitido o descarregamento para uso pessoal, pelo que o emprego do(s) título(s) descarregado(s) para outro fim, designadamente comercial, carece de autorização do respetivo autor ou editor da obra.

Na medida em que todas as obras da UC Digitalis se encontram protegidas pelo Código do Direito de Autor e Direitos Conexos e demais legislação aplicável, toda a cópia, parcial ou total, deste documento, nos casos em que é legalmente admitida, deverá conter ou fazer-se acompanhar por este aviso. 
MPRENSA DA

UNIVERSIDADE

DE COIMBRA

COIMBRA

UNIVERSITY

- PRESS 


\title{
HEALTH EDUCATION FACTSHEET ON MENTAL HEALTH IN THE ELDERLY
}

\author{
Ana Teresa de Sousa Reis ${ }^{49}$, Anabela Correia Martins
}

\begin{abstract}
Health promotion has a crucial role in healthy aging. An important factor for maintaining independence and quality of life of older people is good mental health. To ensure mental health of the elderly, it is important to know the factors that may influence it, in order to promote interventions that include them, intervene on them and prove to be effective.

Based on the document "Healthy Ageing - a challenge for Europe", this study aimed to discuss some determinants of mental health in the elderly, relate them to mental health promotion programs and assess their effectiveness. To this end, 10 scientific articles related to the topic of effectiveness of mental health promotion programs among the elderly were analyzed.

The evidence showed that, to ensure effectiveness, the elderly mental health promotion programs should take into account the factors that influence the mental state of their recipients, must meet the needs of the target audience, and should include an evaluation of their process.

The findings of this study led to the development of a document designated as a "health education page", which contains clear and simple information about the topic of the promotion of mental health in the elderly, specifically regarding the caregiver's health. This document is intended to be a useful instrument for elderly people, caregivers, and professionals.
\end{abstract}

Keywords: Health promotion; Mental health; Healthy aging.

\footnotetext{
49 Escola Superior de Tecnologia da Saúde de Coimbra

Email: anareis83@hotmail.com
} 


\section{Introduction}

The elderly population in Europe has been increasing and it is expected to maintain this trend in the coming years. In 2000, the population over 65 years old represented around 15\%, while forecasts for 2030 point to 24\%, and close to 30\% in 2050 (Draper \& Low, 2004; The Swedish National Institute of Public Health (SNIPH), 2007). In Portugal, the population aged over 65 represented about 16.5\% in 2001, reaching $17.9 \%$ in 2009 (Carrilho \& Patrício, 2010).

Along with population aging, there are also increases the number of elderly people with disability, defined as difficulty in performing daily activities of self-care, compromising independent living and social participation. Impairment causes a decline in the quality of life and increases the risk of hospitalization, institutionalization or even premature death (SNIPH, 2007). In addition, the current society, which is performance-oriented, associates seniors with passivity, deficit, worthlessness, and increased social costs (National Research and Development Centre for Welfare and Health (STAKES), 1999).

Given this notable population aging, the need has become evident to take measures towards the prevention of health conditions associated with aging, and the promotion of health and quality of life of older people.

In 2007, a document entitled "Healthy Aging - a Challenge for Europe" was published by SNIPH, in partnership with the European Commission, of which goals were to review current practices and policies for older people's health across Europe, to review the literature on evidence-based health promotion and study practical interventions to prevent health hazards, and to present the findings on their effectiveness and make these findings accessible to practitioners and policy makers.

Healthy aging was defined in this document as the process of optimizing opportunities for physical, social and mental health, allowing the elderly to have an active role in society, without discrimination, and to enjoy an independent and good quality of life (SNIPH, 2007).

Health promotion has an important role in healthy aging, since it can help prevent health problems associated with aging or make sure 
that elderly people with some of these problems can remain active and independent, preventing institutionalization (SNIPH, 2007).

An important way to maintain autonomy in old age is good mental health and well-being (STAKES, 1999). Specifically, as regards mental health, dementia and depression are the major psychiatric disorders related with aging, with an expected increase in these conditions associated to this age group. Other conditions such as anxiety, schizophrenia, bipolar disorder and disturbances inherent in substance abuse are also prevalent in the elderly (SNIPH, 2007; Draper \& Low, 2004).

According to the International Classification of Disability, Functioning and Health (ICF), from the World Health Organization (WHO), impairment always results from the interaction between the health condition of the individual (with their structural and/or functional alterations, activity limitations and social participation restrictions) and the factors inherent to the context in which the individual lives, which can be intrinsic or extrinsic to the individual (personal or environmental) (WHO, 2001). Thus, to ensure the mental health of older people, it is important to know the factors that may influence the mental state of the elderly, in order to promote programs that engage them and act at their level.

Based on the document "Healthy Ageing - a Challenge for Europe", this paper aims to discuss the factors that may influence older people's mental health, to relate them to mental health promotion programs and to assess their effectiveness.

\section{Methodology}

This study was based on the document "Healthy Ageing - a Challenge for Europe", respecting its structure and methodology. Additionally, it was based on the reading and analysis of 10 scientific papers (systematic reviews, meta-analysis and randomized controlled trials (RCTs) on the topic "mental health in the elderly." The research was carried out in several databases and search engines (Scielo, Cambridge Journals, Allacademic, Google Scholar, etc.), using key words and phrases such as 
"mental health", "elderly", "health promotion" and "aging". We considered the following inclusion factors: relevance, publication date after 1998, the nature of the study (science), the language (English or Portuguese) and the availability of the full text.

\section{Discussion}

After reading the surveyed articles, in respect of the structure of the document "Healthy Ageing - a Challenge for Europe" and the proposed objectives for this study, we now explore some factors inherent in older people and their context, which may restrict their mental health, and subsequently we discuss the effectiveness of interventions to promote mental health in the elderly.

\section{Determinants of mental health in the elderly}

The stigmatization of the elderly is present in most societies. Stigma and discrimination related to mental disorders are also common and are strongly associated with suffering, disability and economic losses. When the target of discrimination is the elderly person with mental illness, there is a double loss for the individual. The consequences of this problem, among others, are the establishment of prejudices and stereotypes regarding the elderly (weak, bizarre, dangerous, useless, etc.), feelings of shame, low self-esteem and reluctance to seek healthcare by the discriminated person. Discriminatory attitudes often extend to families and caregivers, and are reflected in the poor quality of care or lack of access to health services (Graham et al., 2007). The project Key Concepts, developed by STAKES (1999), which aimed to develop a model for the promotion of mental health in Europe, includes in its recommendations the prevention of stigma and discrimination against the elderly.

On the other hand, participation of the elderly in significant activities, public, private or in the family is seen as an important way of maintain- 
ing their mental capacities. In some European societies, the elderly are seen as an important resource, particularly in the support for younger generations (children and grandchildren, for example) in family activities, or even in their work in non-governmental organizations (STAKES, 1999). This aspect is important for maintaining good mental health and well-being since the elderly feel they are contributing to society, although sometimes they find barriers to this type of public or private social participation (SNIPH, 2007).

Personal relationships are considered in the literature as a key factor on mental health in the elderly. Isolation and loneliness are risk factors for mental health decline of the elderly (SNIPH, 2007). In many European countries, most elderly people are living alone and about 50\% suffer from loneliness and social and emotional isolation (STAKES, 1999). The importance of fighting loneliness and social isolation in the elderly is recognized in order to promote their well-being and quality of life. Regarding social networks, the evidence shows that social relations have a major impact on mental health (Antonucci, 2001; Krause, 2001; Russell \& Cutrona, 1991, cited by Fiori, Antonucci \& Cortina, 2006). In the elderly population, more than the size of the social network, the nature of the relationships is determinant, since their social relations may be particularly heterotypic. On a study about the typology of social networks and their implications on older people's mental health, more diverse social networks had better results in terms of depressive symptoms, while the most restricted had worse results. In addition, it was found that mental health benefits from belonging to a diverse network that includes friends and it is due, in part, to the fact that these individuals perceive greater care and attention from its members than individuals belonging social networks which are more restricted and limited to the family (Fiori et al., 2006). The implementation of health promotion programs intended to alleviate the loneliness and isolation is therefore considered of great importance, and to promote the development, improvement or maintenance of social contacts (Cattan, White, Bond \& Learmouth, 2005).

Physical health status is also, unquestionably, an influential factor on the mental status of the elderly. The practice of physical activity is 
pointed out specifically as a key facilitator of good mental health. Among other benefits, physical activity is associated with better cognitive functioning, higher levels of life satisfaction and self-perceptions, and a lower prevalence and severity of anxiety and depression symptoms (Berger, Pargman \& Weinberg, 2007; Colcombe \& Kramer, 2003; Reifschneider, 1998; Schechtman \& Ory, 2001, cited by Fernandes, Vasconcelos-Raposo, Pereira, Ramalho \& Oliveira, 2009). Other evidence also demonstrates the positive relationship between physical exercise and improvement of some mental illnesses, including depression (Deslandes et al., 2009).

By contrast, poverty, in particular homelessness, is a leverage factor of mental illness in the elderly. Mental illness is associated with homelessness, either as cause or consequence, as we can verify in the literature that mental disorders are very common in the homeless elderly. Although it is established that access to healthcare services protects against the negative effects of poverty and homelessness (Hwang, 2000; Stark, 1992, Kessler et al., 1997, cited by Limbo \& Joyce, 2009), the truth is that access to them by these individuals is limited (Limbo \& Joyce, 2009).

Violence against the elderly, defined by WHO as "acts or omissions committed once or many times, damaging the physical and emotional integrity of the elderly, preventing the performance of their social role" (WHO, 2004, cited by Valadares \& Souza, 2010), is another factor conditioning the mental health of the elderly (Gaioli \& Rodrigues, 2008). Feelings of guilt, shame, low self-esteem and fear of retaliation lie behind the abused elderly (Gonçalves, 2006). The role of the caregiver must be stated, often the aggressor, and who the literature associates with the tense nature of the elderly-caregiver relationship, and states that the caregiver only becomes the offender when he/she is socially isolated, suffers from depression or other psychiatric problems, or when the bonds of affection with the elderly are weak or when the caregiver was him/herself victim of violence by the elderly (Kleinschmidt, 1997; Rey \& Browne, 2001, cited by Gonçalves, 2006). Also, alcohol and drug abuse enhances the aggressive attitude of the caregiver (Valladares \& Souza, 2010). We can, therefore, deduce that the caregiver must be taken into account when planning mental health promotion in the elderly. Beyond the physical, 
psychological, financial and sexual abuse, neglect is also a form of abuse (Gonçalves, 2006). Evidence shows that older people with mental illness are neglected, not only in the family but also through limited access to health services and social support (SNIPH, 2007, STAKES, 1999).

\section{Effectiveness of interventions for the promotion of older people's mental health}

The effectiveness of psychotherapeutic and psychosocial interventions in the improving of psychological well-being of the elderly is described in the literature (Pinquart \& Sörensen, 2001, cited by SNIPH, 2007).

The document "Healthy Ageing - a Challenge for Europe" lists, among the forms of psychotherapeutic and psychosocial interventions, cognitive behavioral therapy, reminiscence, psychodynamic approaches, relaxation, supportive interventions, control enhancement, psycho-educational treatments, activity treatments and training in cognitive skills.

Research shows that cognitive behavioral therapy (a strategy that includes education, motivational interviewing, relaxation training and coaching skills for problem solving) as a strategy for intervention in anxiety and associated symptoms, is effective in the elderly. One study showed that this type of intervention had better results in improving the severity of anxiety, depressive symptoms and overall mental health than a support intervention, maintaining the improvement after one year (Stanley et al., 2009). This result is consistent with the guiding document of this paper, which states that interventions to enhance control and cognitive behavioral therapy have an above-average impact on measures of psychological well-being, compared with reminiscence, mixed therapies, supportive interventions, psycho-educational interventions, activity promotion and cognitive training (Pinquart \& Sörensen, 2001, cited by SNIPH, 2007).

A study intended to ascertain the long-term effects of a program to promote mental health in older adults with depression, with a duration of one year, found that over two years, participants in the program felt less depressed, in better physical condition, with better quality of life and more 
satisfied with care. Although the effects of the program, which consisted of pharmacological therapy, behavioral activation, psychotherapy oriented to problem solving and education, reduced after 18 and 24 months (follow-up), they remained up to one year after the program (Hunkeler et al., 2006).

According to a study referred to in the guiding document, it was found that relaxation has a greater impact than supportive care, psycho-educational interventions, activity promotion and cognitive training. In addition, individual interventions were associated with significantly greater improvements in psychological well-being, compared with group interventions, as well as interventions aimed at institutionalized elderly also promoted significantly greater improvements compared with interventions in the community. Interventions carried out by professionals specialized in Geriatrics were more effective than those carried out by professionals without expertise in this area (Pinquart \& Sörensen, 2001, cited by SNIPH, 2007).

Relating the determinants of mental health with the health promotion programs for the elderly, there are some interventions that target specific factors. Two systematic reviews have studied the effectiveness of health promotion programs aimed at preventing or alleviating the loneliness and social isolation of older people (Cattan et al., 2005; Findlay, 2003), a factor which was identified previously as a determinant of mental health in this population. In the review conducted by Cattan et al. (2005), it was found that the most effective programs were those carried out in groups, involving an educational or training component, and social activities aimed at specific groups. On the other hand, the interventions which were less effective were the individual, and those performed at home. Both studies found that programs that allow the active involvement of seniors in the planning, development and implementation of activities, interventions carried out in pre-existing community resources, and interventions that include a process evaluation proved effective. Findlay (2003) also notes the importance of training the facilitators/coordinators of interventions as a determinant of their success.

Physical activity appears to be important to alleviate the effects of aging on physical, social and mental health, and to promote functional independence and autonomy. Increased levels of physical activity allow 
an improvement in perceptions of continuous development, personal enrichment, life satisfaction and self-esteem (Fernandes et al., 2009).

One study indicates that elderly patients undergoing a personalized program of physical activity, with a frequency of three times a week for four months, significantly decreased the rates on anxiety and depression scales in relation to the initial assessments (Sheikh et al., 2003). Also an RCT which intended to determine the effectiveness of a health promotion program for seniors in the community, in which they were subjected to an intervention directed at multiple risk factors with exercise being a core component for six months, showed that at the end of the program, the group showed improvements in performance indicators, in particular depression scale (CES-D) compared with the control group, which showed a decrease in the indicators (Wallace et al., 1998).

However, the overall results on the effectiveness of exercise programs in preventing or reducing depression in the elderly are inconclusive, to the extent that the findings are conflicting, with significant improvements in some programs and not in others (SNIPH, 2007).

Caregivers of older people with mental illness often suffer from high levels of stress, which can lead to negative repercussions on their mental health, creating an increased risk of depression. The pressure on caregivers in order to disregard their own needs, and the long lasting physical and psychosocial stress to which they are subjected, makes them a risk group for the emergence of physical and mental conditions (STAKES, 1999). Since many need psychosocial and instrumental support, it is important to develop interventions targeted to caregivers to improve their psychological well-being (Donaldson, Tarrio \& Burns, 1998; Livingston, Manela \& Katona, 1996; Dura, Stukenberg \& Kiecolt-Glaser, 1990; Covinski et al., 2003, cited by Mittelman, Brodaty, Wallen \& Burns, 2008; Sörensen, Pinquart \& Duberstein, 2002).

The literature shows that individual psychosocial interventions are effective in reducing depressive symptoms for caregivers of relatives with Alzheimer's disease (Mittelman et al., 2008). In some studies, it appears that psychosocial interventions directed at caregivers have lasting effects and are inexpensive, preserve the caregivers' health and delay institutio- 
nalization of the care receiver until several years after participation in the intervention program (Brodaty, Gresham \& Luscombe, 1997; Brodaty \& Peters, 1991; Mittelman et al., 2007; Mittelman et al., 2006; Mittelman et al., 1996, cited by Mittelman et al., 2008; Brodaty, Green \& Kosch, 2003, cited by SNIPH, 2007). There is also evidence that, in interventions of this type, providing information only to the caregiver is a somewhat less effective strategy and it is, therefore, important to pay attention to the emotional needs of caregivers to adopt strategies that suit them and can be effective (Brodaty \& Gresham, 1989, Marriott et al., 2000; Brodaty, Roberts \& Peters, 1994, cited by Mittelman et al., 2008).

In a 2002 meta-analysis on the effectiveness of interventions in caregivers, intervention studies that included psycho-educational interventions, support, instrumental support, psychotherapy, and interventions with multiple components were gathered. Outcome indicators grappled with the assessment of caregiver burden, depression, subjective well-being, ability and knowledge of symptoms of the care receiver. Psychotherapeutic and psycho-educational interventions were the most effective in all indicators, while the multi-component interventions were effective in three indicators and supportive interventions were effective in two. Psychotherapy (note that it is an intervention directed solely to the caregiver) had a positive impact on symptoms of the care receiver (Sörensen et al., 2002).

These findings are consistent with what is described in the guiding document, as it is noted that the most effective programs were those which involved the elderly and their concerned family, were intensive, and were driven by the needs of caregivers, such as caregiver skills training. Also proved effective were the interventions that included practical support, individual counseling and structured, consistent and durable professional support (Brodaty et al., 2003, cited by SNIPH, 2007). Also, the network of integrated care was proved effective in increasing the possibility of resorting to formal support services, while psychotherapy for caregivers can delay institutionalization of the elderly. The use of computer networks improves self-confidence of the caregiver in decision making, especially in rural communities. Educational interventions with a component of training in coping strategies, in addition to specific information about the health 
condition of the elderly, are more effective than educational interventions without this component (Peacock \& Forbes, 2003, cited by SNIPH, 2007).

\section{Conclusions}

After review and discussion of the studies, and bearing in mind the guiding document, it is concluded that, in fact, the mental health of older people benefits from the promotion of psychotherapeutic and psychosocial programs, individualized and carried out by professionals. This conclusion is also valid for the caregivers/family members, which must be included in these approaches. Regarding the effectiveness of physical activity programs for the prevention or reduction of depressive symptoms, although it is proven that physical activity has an important effect on the improvement of depression, it cannot be said that mental health promotion programs including physical activity are effective.

Interventions to promote mental health of the elderly must take into account the factors that influence the mental state of their recipients, and must be specifically directed to the factor or factors on which we intend to work. They must also meet the needs of the target audience, which may be not only the elderly but also their caregivers. These needs can be psychological, emotional or even practical. To achieve effective interventions, participants should be active elements in the planning, development and implementation.

Interventions should also include a form of evaluation of their process in order to perceive if the expected results are achieved or not and why, and the results of this evaluation, positive or negative, should be disseminated, so that the mistake of continuing to promote interventions which have proved to be ineffective isn't repeated.

Also in order to respond to the specificities of this population, further research is recommended on care providers and minorities within the elderly population.

In general, recommendations at the European level go towards the promotion of autonomy, specifically the development of programs to 
promote self-sufficiency, and the development of effective and feasible preventive measures.

As a practical result of this study, we created a support tool called "Health Education Factsheet" (Figure 46), which contains useful, simple and clear information on the promotion of mental health of caregivers of older people with mental illness. This tool is intended to be a vehicle of simple and accessible information, for both professionals and caregivers, or even for the elderly themselves.

\section{with mental illness \\ The age-related mental disorders, including dementia and depression, are compromising factors to the autonomy of the elderly, leading to the need for care provided by others. Caregivers of older people with mental illness, mostly families, are an important element in the prevention of institutionalization. However, these caregivers often suffer from high levels of stress, which can lead to negative effects on their health and on the health of the elderly. The pressure on caregivers in order to disregard their own needs, and the physical and psychosocial stress to which they are subjected, makes them a risk group for the emergence of physical and mental problems, including depression. Thus, as these individuals need psychosocial and instrumental support it is important to develop interventions targeted to caregivers in order to improve their psychological well- being.}

Promoting the health of caregivers of elderly people

Where to act
- Caregiver's depressive symptoms
- Caregiver's physical health
- Caregiver's burden
- Skills and knowledge about the health condition of the
elderly
- Elderly-caregiver relationship
- Caregiver's subjective well-being

Strategies to adopt

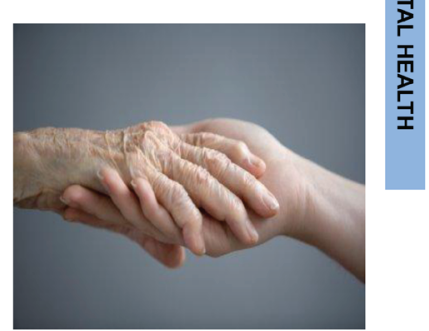

\section{Contacts}

- APFADA - Associação Portuguesa de Familiares e Amigos de Doentes de Alzheimer

www.alzheimerportugal.org

- APP - Associação Portuguesa de Psicogerontologia wuw.app.com.pt

\section{For further information}

Please check Dossier "10 topics for Healthy Ageing

Ana Teresa de Sousa Reis, Physiotherapist

(anareis83@hotmail.com)

- Educational interventions: involve the provision of information about the health condition of the elderly, and useful resources and services

- Coping skills training: caregiver skills training to deal with situations related to the disease

- Instrumental support: provision of professional assistance in healthcare in order to free the caregiver temporarily

- Supportive interventions: based on support groups led by professionals or by peers, creating a space for discussion of problems or feelings

- Psychotherapy: the therapeutic relationship between the caregiver and a specialist following a cognitive behavioral approach

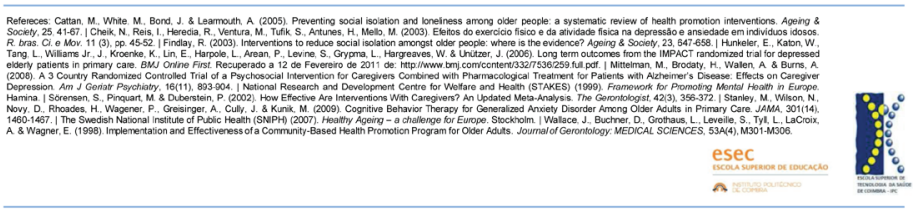

Figure 46: Health Education Factsheet 


\section{References}

Carrilho, M., \& Patrício, L. (2010). A Situação Demográfica Recente em Portugal. Revista de Estudos Demográficos, 48, 101-145.

Cattan, M., White, M., Bond, J., \& Learmouth, A. (2005). Preventing social isolation and loneliness among older people: a systematic review of health promotion interventions. Ageing \& Society, 25, 41-67.

Cheik, N., Reis, I., Heredia, R., Ventura, M., Tufik, S., Antunes, H., \& Mello, M. (2003). Efeitos do exercício físico e da atividade física na depressão e ansiedade em indivíduos idosos. R. Bras. Ci. e Mov. 11 (3), 45-52.

Deslandes, A., Moraes, H., Ferreira, C., Veiga, H., Silveira, H., Mouta, R., Pompeu, F., Coutinho, E., \& Laks, J. (2009). Exercise and Mental Health: Many Reasons to Move. Neuropsychobiology, 59, 191-198.

Draper, B. \& Low, L. (2004). What is the effectiveness of old-age mental health services? WHO Regional Office for Europe. Recovered at $13 \mathrm{Feb}, 2011$ from http://www.euro.who. int/__data/assets/pdf_file/0008/74690/E83685.pdf.

Fernandes, H., Vasconcelos-Raposo, J., Pereira, E., Ramalho, J., \& Oliveira, S. (2009). A influência da actividade física na saúde mental positiva de idosos. Motricidade, 5(1), 33-50.

Findlay, R. (2003). Interventions to reduce social isolation amongst older people: Where is the evidence? Ageing \& Society, 23, 647-658.

Fiori, K., Antonucci, T., \& Cortina, K. (2006). Social Network Typologies and Mental Health Among Older People. Journal of Gerontology, 61B(1), 25-32.

Gaioli, C., \& Rodrigues, R. (2008). Occurrence of domestic elder abuse. Rev. Latino-am Enfermagem, 16(3), 465-470.

Graham, N., Lindesay, J., Katona, C., Bertolote, J., Camus, V., Copeland, J., Lima, C., Gaillard, M., Nargeot, M., Gray, J., Jacobsson, L., Kingma, M., Kühne, N., O'Loughlin, A., Rutz, W., Saraceno, B., Taintor, Z., \& Wancata, J. (2007). Redução da estigmatização e da discriminação das pessoas idosas com transtornos mentais: uma declaração técnica de consenso. Rev. Psiq. Clín., 34(1), 33-49.

Gonçalves, C. (2006). Idosos: Abuso e violência. Rev. Port. Clín. Geral, 22, 739-745.

Hunkeler, E., Katon, W., Tang, L., Williams Jr., J., Kroenke, K., Lin, E., Harpole, L., Arean, P., Levine, S., Grypma, L., Hargreaves, W., \& Unützer, J. (2006). Long term outcomes from the IMPACT randomized trial for depressed elderly patients in primary care. $B M J$ Online First. Retrieved February 12, 2011, from http://www.bmj.com/content/332/7536/259. full.pdf.

Joyce, D., \& Limbos, M. (2009). Identification of cognitive impairment and mental illness in elderly homeless men. Can. Fam. Physician, 55, 1110-1111.e6.

Mittelman, M., Brodaty, H., Wallen, A., \& Burns, A. (2008). A 3 Country Randomized Controlled Trial of a Psychosocial Intervention for Caregivers Combined with Pharmacological Treatment for Patients with Alzheimer's Disease: Effects on Caregiver Depression. Am J Geriatr Psychiatry, 16(11), 893-904.

National Research and Development Centre for Welfare and Health (STAKES) (1999). Framework for Promoting Mental Health in Europe. Hamina.

Sörensen, S., Pinquart, M. \& Duberstein, P. (2002). How Effective Are Interventions With Caregivers? An Updated Meta-Analysis. The Gerontologist, 42(3), 356-372. 
Stanley, M., Wilson, N., Novy, D., Rhoades, H., Wagener, P., Greisinger, A., Cully, J., \& Kunik, M. (2009). Cognitive Behavior Therapy for Generalized Anxiety Disorder Among Older Adults in Primary Care. JAMA, 301(14), 1460-1467.

The Swedish National Institute of Public Health (SNIPH) (2006). Healthy Ageing - a challenge for Europe. Stockholm.

Valadares, F., \& Souza, E. (2010). Violência contra a pessoa idosa: Análise de aspectos de atenção da saúde mental em cinco capitais brasileiras. Ciência e Saúde Coletiva, 15(6), 2763-2771.

Wallace, J., Buchner, D., Grothaus, L., Leveille, S., Tyll, L., LaCroix, A., \& Wagner, E. (1998). Implementation and Effectiveness of a Community-Based Health Promotion Program for Older Adults. Journal of Gerontology, 53A(4), M301-M306.

World Health Organization (WHO). (2002). Towards a Common Language for Functioning, Disability and Health. ICF: Geneva. 